NBER WORKING PAPER SERIES

\title{
EFFECT OF INTERNATIONAL COMPETITION ON FIRM PRODUCTIVITY AND MARKET POWER
}

\author{
Jan De Loecker \\ Johannes Van Biesebroeck \\ Working Paper 21994 \\ http://www.nber.org/papers/w21994 \\ NATIONAL BUREAU OF ECONOMIC RESEARCH \\ 1050 Massachusetts Avenue \\ Cambridge, MA 02138 \\ February 2016
}

The authors thank Tim Bresnahan, Penny Goldberg and Frank Verboven for conversations on the topic. The views expressed herein are those of the authors and do not necessarily reflect the views of the National Bureau of Economic Research.

NBER working papers are circulated for discussion and comment purposes. They have not been peerreviewed or been subject to the review by the NBER Board of Directors that accompanies official NBER publications.

(C) 2016 by Jan De Loecker and Johannes Van Biesebroeck. All rights reserved. Short sections of text, not to exceed two paragraphs, may be quoted without explicit permission provided that full credit, including $(\odot)$ notice, is given to the source. 
Effect of International Competition on Firm Productivity and Market Power

Jan De Loecker and Johannes Van Biesebroeck

NBER Working Paper No. 21994

February 2016

JEL No. F10,L1,O30

\begin{abstract}
$\underline{\text { ABSTRACT }}$
We propose a framework to evaluate the potential impact of international competition on firm performance and highlight two points. First, it is important to consider effects on productive efficiency and market power in an integrated framework. The popular concept of (revenue) TFP combines both effects which can lead to problems of estimation and interpretation. Second, greater international competition enlarges the relevant market and can affect both the number and the type of competitors a firm faces, as well as the nature of competition. While it is possible that firms respond by adjusting their production operations, pricing adjustments are all but guaranteed. We contrast three estimation approaches that start, respectively, from the demand side, the product extensive margin, and the production side. We conclude with a few avenues for future research.
\end{abstract}

Jan De Loecker

Department of Economics

307 Fisher Hall

Princeton University

Princeton, NJ 08544-1021

and NBER

jdeloeck@princeton.edu

Johannes Van Biesebroeck

Center for Economic Studies

KU Leuven

Naamsestraat 69

3000 Leuven

BELGIUM

jo.vanbiesebroeck@econ.kuleuven.be 


\section{Introduction}

A large literature studies the effect of international trade on firm performance. A wide range of performance measures and different ways of international integration have been investigated. In this overview we intend to focus on just two methodological issues. We provide only a partial coverage of the literature, highlighting representative studies that illustrate the main points we want to make.

The first point we emphasize is that it is imperative to study two aspects of firm performance, productive efficiency and market power, in an integrated framework. If all product and factor markets are perfectly competitive, productivity estimates are direct measures of efficiency and they can be studied on their own. Prices equal marginal costs and market power is irrelevant. However, it is hard to deny that perfect competition is the exception. Market power, for example due to product differentiation, is ubiquitous. As emphasized by Katayama, Lu, and Tybout (2009) and De Loecker and Goldberg (2014), this leads to firm-level variation in prices and makes it much harder to determine the meaning of any productivity change as conventionally measured, i.e. capturing the variation in sales not explained by input use. In a domestic context, Foster, Haltiwanger, and Syverson (2008) illustrate explicitly that revenue-based TFP is not a good measure of productive efficiency if firms have market power.

Our focus in this chapter is on correctly decomposing the standard recovered residual of production function into cost, markups and efficiency. Ignoring the different components of measured productivity can lead to misleading conclusions of how competition, and trade liberalization in particular, affect firms and economies as a whole. Rather than measuring productivity as a residual, the methods we review tend to put enough structure on the problem to identify firm-level marginal costs directly. Given sufficient data, changes in marginal cost can be decomposed into changes in efficiency or input prices. However, the level of technical efficiency tends to be less relevant for differentiated products. Knowing what to produce is at least as important as how to produce it.

In most of the paper we do not discuss productivity explicitly in great detail, but that is a deliberate choice. The primitives of the model are firmlevel technical efficiency and demand, and two market-level variables: input prices and the strength of competition. Once one has recovered these, 
it is possible to construct marginal costs and the optimal price-cost margin which in turn determine sales, productivity, and everything else. Rather than estimating productivity directly, we consider it a specific performance measure that might be interesting for some purposes, but not a primitive of the model. As different estimation approaches for productivity can recover a different function of the primitives, a focus on productivity will often hamper comparability of results across studies rather than facilitate it.

Our second point is that trade liberalization, by enlarging the relevant market, has the potential to increase competition. Whether it actually has this effect, and in which cases such effects are strongest is not well understood. Holmes and Schmitz (2010) and De Loecker and Goldberg (2014) survey evidence of the impact of competition on productivity, respectively domestic and foreign competition, but they focus specifically on cases where it is unambiguous that an exogenous change has raised the extent of competition.

Especially in the case of geographic market boundaries, it is natural to consider the strength of competition along a continuous spectrum. A change sufficiently far away will have no effect, but the threshold distance will vary by context. Trade policy changes can have similar effects as lowering of transport costs and therefore naturally influence whether products belong to the same market or not.

The effect of international integration is not always clear-cut. Tariff reductions will only affect a firm if its product competes with the products that benefit. The relevant market definition, both in terms of product characteristics and geographical distance, is not always known. It is not even necessarily constant over time as, for example, a change in technology or transportation costs can implicitly lead to entry of products. Moreover, competition can be itself endogenous to policy. We are concerned with a situation where trade liberalization, broadly defined, has the potential to affect the competition firms face, but where one still needs to verify whether it actually does.

The two issues, the impact of market power on the interpretation of productivity and the impact of trade on competition, are related even beyond measurement. Empirical studies have emphasized that trade liberalization raises average productivity by raising the minimum productivity threshold for survival; and by inducing reallocation of resources towards more pro- 
ductive producers. However, incorporating market power also changes the theoretical gains from trade. In a situation with heterogeneous firms and variable markups, the net effect on welfare crucially depends on which firms take advantage of the exporting possibilities and which firms see the largest increase in competition due to imports. Arkolakis, Costinot, Donaldson, and Rodriguez-Clare (2015) show that adding a pro-competitive effect in the Arkolakis, Costinot, and Rodriguez-Clare (2012) framework lowers welfare gains from trade, while in the oligopoly model of Edmond, Midrigan, and $\mathrm{Xu}(2015)$ the effect goes the other way.

Traditionally, the Industrial Organization (IO) literature has focussed on market power questions, often imposing constant marginal costs on the analysis. In contrast, the trade literature has by and large interpreted observed productivity growth as greater efficiency, which is only valid under perfect or monopolistic competition. The remainder of this chapter illustrates that the two approaches are complementary and that several studies have already blended insights from the two literatures.

In the remainder of the chapter we discuss, in turn, three approaches to estimating the extent of market power. First, in Section 3, we discuss the dominant IO framework that starts from a well-defined demand system. In Section 4 we discuss an alternative approach that exploits the zero profit condition governing equilibrium market entry and exit. In Section 5 we discuss the production-side approach that relies on input choices and refrains from specifying the relevant market upfront. To highlight the different assumptions the alternative approaches make with respect to market definition, we discuss this first briefly in Section 2. Section 6 closes with a few concluding remarks and avenues for further research.

\section{Market Definition}

Defining the relevant market has been at the forefront in the IO literature on estimating and analyzing market power. The development of flexible models of consumer demand was in part to help determine the relevant market. In particular, products belong to the same market, in geographical or product space sense, if consumers consider them to be good substitutes and therefore have non-zero cross-price elasticities. We can use an estimated demand system to investigate these elasticities, but the estimates themselves are inherently conditional on a particular sample of products. 
Therefore it is indispensable to conduct some robustness analyses.

Defining the market is also critical when studying market structure more generally, as variation in the number of firms in a market is one aspect of the strength of competition. To avoid problems associated with at least partly integrated markets or with imports and exports, a range of applications study local service markets where markets can be straightforwardly segmented geographically, see for example the studies by Bresnahan and Reiss (1991), Syverson (2004), and Schaumans and Verboven (2015) which we discuss below.

The IO approach of clearly delineating markets is in contrast to the international trade literature where the gains from integration is a central research theme. Lowering trade barriers or reducing transportation costs enlarges the market and can impact the competitive pressure on firms. It implies that the market definition itself can be endogenous to a change in the economic environment. In practice, however, empirical work in trade has also relied on an implicit market definition. A set of producers operating in a industry as classified by statistical agencies are pooled together and national boundaries are considered as discrete market barriers.

The literature on exchange rate pass-through has taken a different approach and it is precisely interested in the extent to which markets are segmented or integrated. See Goldberg and Knetter (1997) for a survey on this approach. In particular, price and cost variation across markets (typically countries) in response to exchange rate shocks is used to infer the degree of segmentation across markets.

The production-side approach we propose does not require one to commit to a specific market definition to study the effects of competition on firm performance. It allows for the usual productivity effects, but also for additional effects from competition on price-cost markups. The method does, however, crucially rely on the ability to pool firms and products that produce with a common production technology. To identify the extent of market power an individual firm has, we need to measure the output elasticity of a variable input at the observed combination of output and inputs. To recover this we specify a flexible production technology and we need to estimate this using a sample of firms actually employing this technology. Once we have estimates of productivity and market power we can relate these to changes in competition, for example as triggered by trade policy changes. 


\section{Estimating competition from the demand side}

In this section we describe the so-called demand approach to analyze the impact of competition, be it domestic or international in nature, on firm performance. As mentioned before, we always consider firm performance to include not only technical efficiency, but also marginal cost of production and the ability to mark up, which are components of the usual productivity measures. A first step in this type of analysis is to estimate demand, which we review first. Studies of the impact of international competition have, in a second step, supplemented the estimated demand system with a behavioral assumption on market competition to perform counterfactual simulations of trade policies, which we review next. The existing literature focuses mostly on price effects and markups, but given that marginal costs and counterfactual market shares are recovered other types of analysis are possible. We review some extensions in the third sub-section and revisit potential applications that are more directly linked to the productivity literature as an avenue for future research at the end of this chapter.

\subsection{The standard framework: Discrete choice demand}

Many applications in field of industrial organization require knowledge about firms' own and cross-price elasticities. Berry (1994) sets out a powerful framework of how to estimate very flexible elasticities in differentiated goods markets with many products using only aggregate, product-level information: quantities, prices and other characteristics. It starts from a random indirect utility function that is a function of observable product characteristics, including price, as well as idiosyncratic consumer-specific tastes. Assuming that consumer-level tastes are distributed according to an extreme value distribution, choice probabilities can be aggregated over consumers to obtain an explicit expression for the market shares of all products.

The application in Berry, Levinsohn, and Pakes (1995) for the US automobile market uses a random coefficients demand system that incorporates consumer heterogeneity in the valuation of product characteristics. The results demonstrate that even with tightly parameterized preferences that can be estimated using only market-level data, the discrete choice model can still generate very flexible substitution patterns between products. Demand curves are continuous at the market level and incorporate the intu- 
itive feature that substitution is stronger between products that are similar in characteristics space.

In principle, the demand model can be estimated without any supply restrictions. The supply side of the market can help mitigate the price endogeneity, as firms are likely to set prices taking into account unobservable product quality which enters the residual of the demand curve. Berry, Levinsohn, and Pakes (1995) use the characteristics of competing products to construct instruments for price. In order to increase estimation precision, they supplement the demand system with a set of first order conditions derived from profit-maximizing price setting behavior and a Nash equilibrium assumption. Firms take into account how each price they set influences sales of all their own products as well as the strategic responses of other firms 1

In addition to relying on an explicit supply model to calculate markups, it allows for counterfactual analysis by changing a primitive of the model. An important application is in merger analysis where the effect of a potential merger on the market equilibrium is predicted ex ante. Using an explicit behavior assumption, one can recover the product-level marginal costs that are consistent with the estimated demand model and the observed prices. A merger affects the equilibrium because the merging firms have an incentive to raise prices as their multi-product price setting behavior now takes into account demand-stealing over an increased set of own-products. Firms not party to the merger are also likely to raise prices in response as prices tend to be strategic complements. Possible efficiency gains from the merger can readily be incorporated in the analysis as lower marginal costs for the directly affected firms.

The entire analysis starts from a well-defined product market, populated by a set of consumers with stable preferences. Different behavioral assumptions directly imply different strengths of competition. Assuming that firms behave as oligopolists leads to a prediction of positive pricecost markups, while assuming price-taking behavior directly fixes marginal costs to the observed prices. The Cournot assumption of quantity competition leads to a positive markup even for homogenous products, while the Bertrand assumption of price competition requires some product differentiation before prices can exceed marginal costs. The product-level marginal

1 Reynaert and Verboven (2014) take derivatives of the entire set of first order conditions to obtain optimal instruments for the price. 
costs that are backed-out as primitives of the model will depend on the specific behavioral assumption used and the particular functional form assumptions.

In another application to the automobile industry, Bresnahan (1987) jointly estimates demand and marginal cost parameters under different assumptions for the mode of competition. One criterion to assess the appropriateness of alternative assumptions is to use a non-nested test to compare the fit with the data. An alternative criterion is to estimate the model separately for each year and verify which sequence of market conduct assumptions leads to the greatest parameter stability. The results indicate that parameter estimates for demand and marginal cost, the primitives of the model, are very similar in all three years if one derives the first order conditions assuming monopoly pricing in 1954 and 1956, but BertrandNash pricing in 1955. The data thus suggests that a collusive arrangement in the industry broke down for a single year when firms' behavior is well explained by a change to oligopoly pricing with stable preferences and production technologies.

A difficulty is that it is not straightforward to model the mode of competition as varying in a continuous fashion with a parameter to be estimated. An older literature in IO considered conjectural variation games, but Corts (1999) illustrated that in a more general dynamic context a range of competitive situations are consistent with the same value of the conduct parameter. Nevertheless, Genesove and Mullin (1998) show that with a freely varying conduct parameter their model leads to price-cost markups in line with those obtained directly from marginal costs which are observable in their application to the sugar refining industry. They further show that the marginal costs one can back-out of a fully specified structural model are sensitive to the particular behavioral assumption used to derive the firms' first order conditions. They are, however, not very sensitive to the functional form assumption of the demand system.

From a purely empirical standpoint, one would gauge the competitiveness of a market by the average prevailing price-cost margin. But unless one is willing to take accounting data at face value, which Genesove and Mullin (1998) argue is valid in some (rare) situations, one already needs to make a behavioral assumption to recover marginal costs as outlined above. Even if demand were estimated separately, different assumptions on the mode of competition will lead to different price-cost markups and differ- 
ent conclusions.

In practice, the literature has by and large adopted the flexible assumption of a Nash equilibrium in prices for strategically behaving multi-product firms. This particular 'mode of competition' or 'behavioral assumption' can accommodate markets with different levels of competitiveness by varying the distance between goods in product space. Higher price sensitivity of consumers, higher cross-price elasticities, and less concentrated ownership of products will all increase the elasticity of a firm's residual demand and in turn lower equilibrium price-cost markups.

\subsection{Evaluating trade policy using counterfactual simulations}

The above framework has been used to evaluate the economic impact of trade policies or to study other questions of interest to the trade literature. Any change in a primitive of the model will influence the strength of competition each firm faces as the observed equilibrium is supported by the intersection of best-response functions of all market participants. To predict likely effects of a policy change, researchers calculate a counterfactual market equilibrium that again leads to a situation no firm unilaterally wants to deviate from.

To accomplish this, the estimated demand model is supplemented with an explicitly specified behavioral model that generates a system of first order conditions, one for each firm. The most common assumption is that firms set prices according to a multi-product Bertrand pricing game. The observed market shares and prices then imply a set of marginal costs for which the data is consistent with profit maximization given the assumed behavior. After changing a primitive, e.g. the tariff wedge incurred by imports from one country, re-solving the system of first order conditions leads to a new equilibrium price vector for all products, which in turn implies a new set of market shares.

A wide range of trade policies have already been evaluated in this framework. The automobile industry has been the proving ground as it fits the assumption of an oligopolistic market structure and has rich data that is widely available. The most straightforward application is a unilateral reduction in import tariffs which lowers the relevant marginal cost that firms take into account when determining the profit-maximizing prices for their goods on an export market. Tovar (2012) studies the welfare effects of such 
a tariff reduction on the Colombian automobile market. The model predicts very large benefits, around \$3,000 per car purchaser, arising mostly due to greater variety.

Other studies have looked at the same question in the context of the establishment of a Preferential Trade Area. Brambilla (2005) studies the Customs Union between Argentina and Brazil; Park and Rhee (2014) study two Free Trade Agreements (FTA) from the Korean perspective, one with the United States and one with the European Union; Gao, Van Biesebroeck, and Verboven (2014) study FTAs between Canada and several potential FTA partners, including the European Union, Japan, Korea and China.

The impact of the Voluntary Export Restraints (VER) that Japanese firms agreed to on their US and EU exports are a variation on this theme. Goldberg (1995) introduces VERs into the importers' first order conditions through a Lagrange multiplier on aggregate Japanese imports ${ }^{2}$ Berry, Levinsohn, and Pakes (1999) model the VERs as a specific tariff on the targeted imports. In both cases, they amount to an implicit tax on Japanese cars. The average impact on marginal cost can be estimated using a sample period that includes both years when this type of protectionism was in place and years when it was not. As the fully specified structural model provides information on consumer welfare, domestic firm profit and government revenue, it can be used to evaluate whether the imposition of VERs was a welfare improving US policy or not.

Still focusing on the automobile market, Fehrstman and Gandal (1998) study the effect of the Arab boycott on the Israeli market. In this case, the counterfactual, post-boycott equilibrium is not characterized by different marginal costs, but by the removal of Japanese and Korean car models from the market. Goldberg and Verboven (2001) use the same framework to study international price dispersion in the European car market. Exploiting the fully specified structural model, they can simply eliminate one potential explanation for the observed cross-country price differentials and verify how much prices are predicted to change.

In other differentiated goods industries, Irwin and Pavcnik (2004) evaluate the impact of the 1992 US-EU agreement that limited subsidies in the global market for large passenger airplanes. They show that the observed

\footnotetext{
${ }^{2}$ It implies that all Japanese firms internalize the constraint they face on their joint exports, something that is not implausible given the important coordinating role played by the Japanese Ministry of International Trade and Industry (MITI).
} 
price change in the market equilibrium, an Airbus-Boeing duopoly, is similar to what would be expected from a $5 \%$ increase in marginal cost. Kitano and Ohashi (2009) assess to what extent the strong recovery of HarleyDavidson in the US motorcycle market could be explained by the safeguard provisions applied by the United States. A counterfactual simulation of the likely effect of the US' imposition of temporary tariff protection of $45 \%$ suggests that this alone cannot explain much of the sales boost as consumers perceive Japanese motorcycles to be rather poor substitutes.

A few studies use the discrete choice demand framework to study gains from trade more generally. Friberg and Ganslandt (2006) do this in the context of simultaneous imports and exports of bottled water by Sweden. They use the random utility model implied by their estimated demand system to quantify the value of increased product variety, a first source of welfare gains. The welfare gains from the pro-competitive impact of imports on domestic prices is computed in a counterfactual simulation that eliminates all imports from the market. They find that the benefits through these two channels outweigh any plausible resource cost from international trade. Sheu (2014) investigates the same question in the Indian printer market. Following its entry into the WTO and the gradual elimination of an import tariff of $20 \%$, the country experienced a large increase in imports. The relative importance of three possible factors that could boost welfare-lower price, higher quality, and greater variety-are assessed without a counterfactual analysis. She finds that higher quality of imports was the most important channel for welfare gains from trade ${ }^{3}$

Khandelwal (2010) also does not perform a counterfactual simulation, but uses the residuals from the estimated demand system as proxies for product quality, in line with the structural interpretation of Berry (1994). The novelty is that he only uses widely available product-level trade information and the Armington assumption-which implies products are (only) horizontally differentiated by their country of origin - to estimate the demand system. He considers imports from each country as a different product variety and products are defined as all 10-digit HS category by country interactions. He then estimates demand for a large number of 'markets', pooling all 'products' in a 4-digit HS category. The results highlight that these product markets vary substantially in their scope for quality differ-

\footnotetext{
${ }^{3}$ This contrasts with the finding for the Colombian car market in Tovar (2012) which stressed the importance of increased variety.
} 
entiation.

Gao, Van Biesebroeck, and Verboven (2014) use similarly estimated demand systems for several product markets to evaluate the impact of an FTA between Canada and potential partners. Rather than perform counterfactual simulations in each market, they calculate the marginal effect of tariff reductions on consumer surplus, domestic profits and government revenue. They use the estimated demand systems, but perform a partial equilibrium analysis only calculating first-round effects from the initial price reductions of affected imports. For the automobile industry, the most important category of differentiated goods by import volume, they compare the predicted welfare effects using both approaches. With only a few exceptions, the sources of welfare gains from different FTAs are estimated remarkably similar with the fully-fledged counterfactual simulation using detailed product information and the partial equilibrium calculation using trade data.

\subsection{Possible extensions}

\subsubsection{Reallocation}

In the trade literature there has been a lot of theoretical work, starting with Melitz (2003), showing that the reallocation of market share from less to more productive firms boosts aggregate welfare. In the setup of (Arkolakis, Costinot, and Rodriguez-Clare 2012), this type of market share reallocation together with utility gains from increased product variety are the primary channels through which trade raises aggregate welfare.

Existing empirical exercises, see for example Pavcnik (2002) and Eslava et al. (2004), have evaluated the impact of trade policy on aggregate productivity through a reallocation of market share towards more productive firms. A thorny issue is that measures of productivity confound productive efficiency and market power. This is an inherent problem since researchers rely on (deflated) sales to proxy for output, which except in the case of price-taking firms or product homogeneity leaves price variation unaccounted for and therefore captured by the productivity residual. CollardWexler and De Loecker (2015) illustrates that the results from such a reallocation analysis are extremely sensitive to whether one controls for price variation, both output and input prices, or not. While we are incorrectly measuring the underlying mechanism, the alignment of productivity to 
market shares, it is important to note that the lack of producer-level price data does not invalidate the aggregate (say industry-wide) productivity effects.

If one were to calculate a counterfactual equilibrium along the lines described in the previous section, it would be straightforward to isolate the effects of reallocation on the strength of competition in a market. Such a calculation generates a full vector of new prices and market shares for all active firms. The effect of reallocation on the sector's average price-cost margin, a weighted average of the product-level margins, can be readily computed in this framework. Moreover, one can decompose the aggregate change into a change in product-level markups and a change due to shifting weights in the aggregation. Even if the marginal cost of each product remains unchanged after a trade policy change, the average marginal cost among active firms or products is likely to change due to differences in product-weights $\left.\right|_{4} ^{4}$

It is not hard to predict what the expected effect of a tariff reduction should be. Highly productive foreign producers have low intrinsic marginal costs, but import tariffs inflate the relevant, landed marginal cost on their export markets. This form of protectionism depresses their market share and diminishes the strength of competition for domestic firms which can price higher. Heterogeneous firm models of trade predict that the most productive foreign firms will enter export markets first. Lowering tariffs will thus reallocate market share away from less productive (domestic) firms to more productive imports. The magnitude of this effect can easily be investigated using a counterfactual simulation of a new market equilibrium under the assumption of a reduced import tariff.

\subsubsection{Productivity effects}

The above framework can provide a direct estimate of the effect of any trade policy change on the price-cost margin. If marginal costs are assumed to be constant over time or to vary only idiosyncratically, it is by construction purely a market power effect. The average cost in a sector can change due to weighting, but firm-level or product-level changes do not contribute to aggregate welfare.

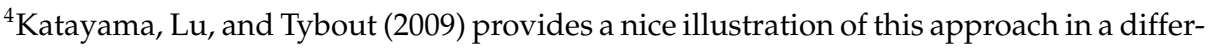
ent context, namely to evaluate the productivity gap between exporters and nonexporters. 
Another strand of the trade literature has found important productivity effects of domestic trade liberalization. Amiti and Konings (2007) show that lower input tariffs raise firm-level total factor productivity (TFP) in Indonesia. De Loecker, Goldberg, Khandelwal, and Pavcnik (2012) show that in India a similar effect on TFP should not be interpreted as higher efficiency, but as incomplete pass-through of input price reductions. Brandt, Van Biesebroeck, Wang, and Zhang (2014) show for China that even controlling for input tariffs and price changes, lower output tariffs did raise productivity. They argue that state-owned firms in particular were forced to increase efficiency to avoid bankruptcy in the face of stronger import competition.

In the methodological framework outlined in this section, a particular behavioral assumption has to be used in a counterfactual simulation, but one can already impose it at the estimation stage. Jointly estimating the demand and supply sides would increases estimation efficiency and guarantee that the demand estimates are consistent with profit maximization, e.g. generate an own price absolute elasticity of at least one. In addition, it allows one to recover how marginal costs vary with observable variables. For example, Berry, Levinsohn, and Pakes (1995) and Bresnahan (1987) include input factor prices in the functional form specification of marginal costs.

When price effects of a potential merger are calculated in a merger analysis that precedes the actual merger, one can include a direct effect of the merger on marginal costs. Such an exercise can reveal for example how large of an efficiency gain is needed to avoid price increases following a merger. One could similarly include import tariffs directly in the marginal cost specification to incorporate potential productivity gains from trade liberalization in the model. Such a specification can provide some sensitivity analysis on the predicted effects of trade liberalization if one has outside information on likely efficiency effects.

The studies reviewed in Section 3.2 calculate the counterfactual equilibrium assuming that marginal production costs stayed constant. As a result, any productivity effects have to be due to changes in output prices. When the industry is observed both before and after the policy change, it would be straightforward to back out marginal costs for each product-year observation from the first order conditions using unchanged behavior but incorporating the primitive that changed. In a second step, one could then 
verify whether there is a systematic relationship between these costs and the policy change. This approach would be similar in spirit to studies that regress productivity on policy changes, but have the advantage of controlling for changed price-cost margins.

If such effects on marginal costs are present, one could even incorporate them in the model. For example, when evaluating the impact of VERs, Goldberg (1995) and Berry et al. (1999) recover a parameter that captures the implicit tax on Japanese vehicles that such a trade policy implies. Importantly, this parameter is identified assuming unchanged production costs. If policy changes influence efficiency, as for example the learningby-exporting literature suggests, one should allow for such effects in the model when performing a counterfactual exercise 5

In other literatures, a few studies have already followed this approach. Aw, Roberts, and $\mathrm{Xu}$ (2011) allow for a direct efficiency-enhancing effect of export activity on a firm's marginal cost, through its impact on productivity, in line with the learning-by-exporting hypothesis. They do this in a dynamic model where forward-looking firms make both innovation and exporting decisions, but one could also incorporate this in a static model where exporting decisions are exogenous. Hashmi and Van Biesebroeck (2014) investigate the two-way impact of competition on innovation. They allow for higher product quality to boost demand, but the same variable also enters their specification for the marginal production cost.

\section{Estimating competition from product entry}

In this section we focus more specifically on the extensive margin, entry of either firms or products. Opening up to international competition is expected not only to impact firm's intensive margins (like sales, efficiency, etc.), but will also affect the incentives to enter or exit the market, or introduce or drop products. Given that such investments will also impact a firm's organization, product portfolio, and most likely even its cost of production, their effects will thus again show up in standard measures of revenue-based productivity (TFPR). We discuss a common approach in Industrial Organization that relies on equilibrium entry patterns, and we

\footnotetext{
${ }^{5}$ This mirrors the critique in De Loecker (2013) who argues that models failing to find evidence for learning-by-exporting effects often do not allow for the existence of such effects in their specification of the productivity evolution.
} 
draw the analogy to theoretical models in international trade that evaluate the effect of trade liberalization on welfare, typically measured by aggregate (revenue) productivity. In the extensions, we discuss studies that imply an effect of trade-driven market expansion on measured productivity through its impact on innovation incentives, product introductions, and product prices.

\subsection{The standard framework: Geographically isolated markets}

One shortcoming of the demand-side approach is the absence of endogenous entry and exit of products or firms. A trade policy that forces some products from the market can still be evaluated, see for example Fehrstman and Gandal (1998), but one has to specify exogenously which products exit. How firms decide to enter or exit a market is not modeled in the static framework, but this is likely to be an important feature of many trade policies, in particular of trade liberalization. Alternatively, product characteristics may respond to trade liberalization as well, which further complicates such an approach.

A separate strand of the IO literature estimates the strength of competition in an industry solely by exploiting equilibrium patterns of product entry. It avoids explicit functional form assumptions on demand, only specifying that we observe a market-scale factor that is proportional to aggregate demand. The seminal application of Bresnahan and Reiss (1991) specifies the demand for a homogenous good by a representative consumer as $d\left(Z, P_{N}\right)$ and multiplies this with the number of consumers $S(Y)$ to obtain the aggregate market demand $Q$. The vectors $Z$ and $Y$ denote demographic variables affecting market demand. The price $P_{N}$ is indexed by the number of active firms $N$ as firms are expected to set prices taking into account the number of competitors they face ${ }^{6}$

With these minimal assumptions one can learn about the strength of competition in a particular industry simply by comparing the number of active competitors in geographically isolated local markets of different size. In equilibrium, firms will enter as long as they make positive profits. If competition depresses prices, and thus price-cost margins, there will exist a market size threshold $S_{N}$ that is minimally needed for the $N$ th entrant to

\footnotetext{
${ }^{6}$ The per-capita demand and market size shifters $Z$ and $Y$ generate additional variation in aggregate demand, but they are not crucial to the identification strategy.
} 
just break even. The following zero profit condition pins down the market size threshold $S_{N}$ at which the $N$ th entrant just break even:

$$
\pi_{N}=\left[P_{N}-c\left(\frac{Q}{N}, W\right)\right] d_{N} \frac{S_{N}}{N}-F_{N}=0 .
$$

By observing many localized markets that vary in size and number of entrants, a series of thresholds $\left\{S_{1}, S_{2}, \ldots, S_{N_{\max }}\right\}$ can be estimated.

In general, both the average variable cost $c($.$) , which is allowed to vary$ with local factor prices $W$, as well as fixed entry cost $F_{N}$ could vary across entrants or with the scale of production. To distinguish such variation from the dependency of the price on the number of competitors one needs to observe prices or quantities or make behavioral assumptions, e.g. assuming the most efficient firms enter first.

In the absence of firm heterogeneity in technology or costs, the model assumes a constant and uniform marginal cost per unit, the impact of competition can be uncovered directly from the pattern of market size thresholds $s_{N}=S_{N} / N$. This series of thresholds, one for each $N$, indicate how many consumers per firm are needed in a market in order for all $N$ active firms to avoid losses. The ratio of successive thresholds provides a one-toone mapping of the ratios of variable profits per consumer:

$$
\frac{s_{N+1}}{s_{N}}=\frac{\left(P_{N}-c\right) d_{N}}{\left(P_{N+1}-c\right) d_{N+1}} .
$$

If the number of active firms $N$ rises less than proportionately with the market size $S$, it indicates that the price-cost margin falls if additional firms compete in a market. More customers are needed per firm in order for the marginal entrant still to be able to recover its fixed costs. Such a situation will be characterized by $s_{N+1} / s_{N}>1$. As prices gradually converge to marginal costs with increased competition, as happens for example in the Cournot case, the ratio of thresholds converges to one. The relationship between $N$ and $S$ becomes a proportional relationship as price-cost margins do not fall anymore with $N$.

The strength of competition is thus an industry feature that can be identified by observing the same industry in a series of separate markets, for example in geographically isolated local markets. One measure of market competitiveness would be the number of firms needed for the $s_{N+1} / s_{N}$ ratio to become insignificantly different from unity. For a given number of 
firms, the slope of the $N-S$ relationship is a direct measure of the strength or the lack of competition. Once the relationship is proportional and the threshold ratio has converged to unity, market power has been exhausted.

An important caveat is that the above relationship is identified from variation in the number of active firms across markets of different size, which is interpreted as variation in the price-cost margins. The framework does not allow one to distinguish between perfect competition and perfect collusion as the profitability level is not identified. In either case the markup would not vary with the number of active firms in the market. Moreover, a monopolistically competitive market with horizontal product differentiation would only look different from perfect competition if the residual demand each firm faces has a variable elasticity. The case of a constant elasticity of substitution (CES) demand at the individual level would be indistinguishable from perfect competition irrespective of whether the elasticity of substitution is 1 or 10 . While the price-cost margin would be lower for higher elasticities, the crucial feature is that in both cases it does not respond to the number of active firms.

While evaluating the competitiveness of a market is straightforward once the size thresholds are obtained, estimating the shape of the variable profit function is not so straightforward. Econometric estimation is complicated if one allows firms' entry decisions to depend on the unobservables in the variable profit equation. This seems a plausible empirical feature, but given that each firm's equilibrium strategy in a dynamic entry game depends on the actions of other firms, correlation between unobservables gives rises to an endogeneity problem. Bresnahan and Reiss (1990) discuss identification strategies.

Syverson (2004) exploits a similar idea, but instead of varying the total market size he compares markets that differ in the density of consumers. He studies the market for ready-mix concrete where competition is highly localized (spatially) as firms face a physical limit how far they can ship their final product. As a result, denser markets can support more firms, even conditional on total market size. Comparing regions with different densities generates a similar type of exogenous variation in the number of competitors as comparing geographically isolated markets of different size. Moreover, higher density makes it easier for consumers to switch between producers. It raises product substitutability and further lowers equilibrium price-cost margins. 
To evaluate the extent of competition in an industry, Syverson (2004) does not compare the number of active firms to some absolute measure of market density. Instead, he assumes that firms differ in productivity such that the zero profit condition implies a minimum productivity level a firm needs to attain to be able to operate profitably. In denser markets, more firms will enter and their products will be better substitutes. They will compete more fiercely, lowering price-cost margins and raising the productivity threshold needed for survival. On average, the selection of surviving firms is more stringent in denser markets and the minimum as well as the average productivity levels will be higher.

\subsection{Effect of trade policy on the number of competitors}

This type of comparative statics is similar to the way theoretical models of international trade evaluate the impact of trade on an economy. The market equilibrium is first solved in an autarky situation. The effect of trade is then investigated by comparing this to a situation where the home and foreign markets are merged in a free trade equilibrium with a larger global market. A similar comparison can be achieved by decreasing trade barriers from infinity to zero, which even allows for a comparison with intermediate situations as trade barriers can be varied continuously.

In the homogenous firms literature, following Krugman (1979), an increase in the relevant market size following trade integration is shown to raise output per firm. Due to scale economies in production-constant marginal costs with a fixed cost-the average cost per unit falls. As firms produce on the elastic portion of demand, it induces them to lower prices which raises the real wage and thus welfare. For general demand curves, at the higher output the price elasticity tends to be lower and markups higher. This is a consequence of the higher output and will only offset the output and welfare gains partially, not overturn them.

Much of the subsequent literature, especially once firm heterogeneity was introduced, has assumed monopolistic competition, constant marginal costs, and CES preferences, see Arkolakis, Costinot, and Rodriguez-Clare (2012). This severely limits possible adjustment channels following trade opening. In particular, price-cost margins do not adjust when the number of firms increases, nor does firm-level productivity. Melitz (2003) stresses a different, general equilibrium effect of increased aggregate sales in the 
open economy case. As firms expand output by exporting, they bid up the wage rate forcing less productive firms to exit. Even though firm-specific productivity is constant, greater selectivity raises the average productivity of surviving firms and redistributes labor input towards more productive uses-as in Syverson (2004), Such a market outcome could also be characterized as more competitive, even in the absence of any effect on price-cost margins, as sales are increasingly concentrated in more efficient firms.

Melitz and Ottaviano (2008) use a similar setup, but with quadratic preferences for consumer demand which generates price-cost markups that decline when the market enlarges and more firms compete. As a result, trade-liberalization now has an additional pro-competitive effect on the prices of surviving firms. At the same time, however, the elimination of low-productivity firms from the market reallocates market share towards highly productive survivors. These firms produce further down on their demand curve and will optimally set a higher price-cost margin. Market selection thus raises the average markup over all active firms and this is a drag on aggregate welfare gains, as highlighted by Arkolakis, Costinot, Donaldson, and Rodriguez-Clare (2015).

Eckel and Neary (2010) further generalize this setup by introducing multi-product firms. Consumers still have quadratic preferences over all product varieties, but firms now endogenously decide their scope of production. Their marginal costs are lowest for their 'core' product and rise if they adapt varieties to better serve consumers with horizontally differentiated tastes. Globalization, which is modeled directly as an increase in market size, raises total output but has opposite effects on high and lowcost varieties. The increased competition that accompanies the larger market size leads to a contraction in the production of high-cost varieties some of which will even be discontinued. For low-cost varieties the market expansion effect dominates and their production expands. This raises firmlevel productivity, as firms focus on their core competences, but also raises the average price-cost margin as low-cost, high-margin varieties are more likely to survive. The impact of the increase in market size on the total number of active firms is ambiguous and depends on the substitutability of products.

Other studies have used different assumptions on market demand and production technology to study behavior of multi-product firms. However, they mostly compare only theoretical predictions for the autarky and free 
trade equilibria. The few studies that provide empirical evidence illustrate equilibrium patterns of exporting and product churn, but do not compare directly the number of active firms in markets of different size.

\subsection{Extensions}

\subsubsection{Market expansion}

The trade context seems well-suited to apply the Bresnahan and Reiss (1991) framework for identifying the strength of competition, but to our knowledge this has never been done (yet). From each country's perspective, a lowering of trade barriers its firms face overseas is akin to a market expansion. Lileeva and Trefler (2010) have shown that a decline in US import tariffs increased the productivity of Canadian firms, especially for intermediately-productive firms for which the incentive to make productivity-enhancing investments-in order to boost productivity enough and make it as an exporter-is likely to have increased the most following the change in US trade policy. One could similarly study whether such a change increased the number of viable Canadian firms and in turn the competitiveness in the market.

However, in the context of differentiated goods markets, which is the dominant framework in international trade, it is imperative to take into account that product entry can expand the relevant market size. Schaumans and Verboven (2015) demonstrate that the minimum market size needed for an additional firm to be viable decreases with the number of firms if market expansion, due to product variety, dominates the decrease in pricecost margins due to increased competition. This is a likely outcome in the CES demand case which is a popular assumption in the theoretical trade literature. Profit margins do not respond at all to entry, while the love-ofvariety built into the utility function leads to higher per-capita sales when product variety increases. As a result, the market increment needed to recover fixed costs falls with the aggregate market size. Discrete choice demand specifications have a similar property as new products take away some market share from the outside good and directly expand the market:7

Ignoring this channel leads to an underestimate of the impact of the number of firms on the strength of competition. It also leads some theoreti-

\footnotetext{
${ }^{7}$ See $\overline{\text { Berry and Waldfogel (1999) }}$ for an application to entry in the US radio market.
} 
cal trade models to predict that the overall number of active firms, the sum of home and foreign firms, increases as we move from autarky to free trade, even though the global market size is unchanged and firms compete more directly. In other cases this is merely a possibility if the effect of competition on price does not outweigh the beneficial effects from product variety, see for example Eckel and Neary (2010).

Schaumans and Verboven (2015) illustrate how to correct for this effect when constructing the ratio of successive market thresholds. Their approach requires information on the total revenue per customer in each market. This allows for market expansion, even holding the number of customers in a market, i.e. the potential market size, fixed. Together with the number of active firms, it can be used to estimate an equation for the average revenue per firm as a function of the market size. On export markets this type of information is directly observable, but it might not be readily available on a firm's domestic market.

\subsubsection{Integrating supply and demand}

Abstracting from the need to correct for market expansion, the Melitz and Ottaviano (2008) study bridges the approaches in Berry, Levinsohn, and Pakes (1995) and Bresnahan and Reiss (1991). It features a demand function with varying elasticity and trade policy directly affects markups. However, competition is monopolistically competitive which precludes strategic responses. Moreover, as in most of the trade literature, products are only differentiated horizontally and symmetrically. An exogenous productivity draw for each firm fixes its profitability without any real scope for firm decisions. Greater competition following trade liberalization will force some products from the market, but a zero profit condition for marginal firms is all that is needed to pin down market participants.

This is a natural assumption in the Bresnahan and Reiss (1991) or Schaumans and Verboven (2015) framework, but a more flexible demand system allows for richer forms of differentiation. A few studies connect the two literatures even more closely. They use a more flexible demand system and supplement the model with supply responses. For example, Thomas (2011) conducts a counterfactual analysis to evaluate the loss in variable profits if some laundry detergent variants would be eliminated from the market. Her results suggest that fixed costs of keeping a product in the market have 
to be extremely small to rationalize firm behavior. Goettler and Gordon (2011) and Eizenberg (2014) study new product introductions in the semiconductor and computer industries and the competitive interactions this entails. However, as product introduction is a dynamic decision, the estimation becomes exceedingly complicated.

Dynamic considerations of product entry will also influence pricing in models with market power. Even the mere threat of new product entry can already change current behavior. In a context of international trade, Holmes and Schmitz (2001) and Salvo (2010) provide evidence that firms with market power practice limit pricing to keep out potential foreign competitors.

Similar dynamic considerations apply to the impact of trade policy. It can, for example, generate a different response to temporary versus permanent forms of trade protection. A large literature has shown that firms benefitting from import tariffs tend to have lower productivity, presumably because they face lower incentives to make productivity-enhancing investments, see Brandt et al. (2014) for an overview. However, Konings and Vandenbussche (2008) find the opposite for firms that benefit from temporary trade safeguard protections. They argue that firms will behave differently if they know the import protection will end in the near future. Firms can use temporarily elevated sales and variable profits to take actions that boost productivity and prepare for the expected future competition.

\section{Estimating competition from the production side}

In this section we discuss the so-called production approach to investigate the impact of trade liberalization on firm performance. While this approach delivers an estimate of markups and thus, via price data, an estimate of marginal costs, the standard variable of interest, productivity, is immediately subsumed in this measure. In the absence of variation in input prices and scale effects, variation in marginal costs equals variation in technical efficiency. We highlight that two separate literatures, the trade liberalizationproductivity literature on the one hand, and the international pass-through literature on the other hand, are highly interconnected. It is imperative to study both efficiency and price effects jointly in any analysis of productivity in a context where firms might have some market power. 


\subsection{Identifying market power at the firm level}

Let's now turn back to our original question. We want to know whether greater (international) competition affects firm performance. In terms of performance, we consider both productive efficiency and profitability, as measured by markups.

Increased global competition, say through trade liberalization, has the potential to affect any producer. However, the extent to which a firm is affected by an exogenous change to its operating environment depends on a few factors. First, whether the change in the operating environment is a cost or demand shock, or both. Second, the degree of substitutability across products of the affected industry will play an important role. A reduction of import tariffs for Japanese cars in the United States will affect other car producers differently depending on the substitution patterns across brands and models.

While we might expect a policy change to have a competitive effect on the industry, the effect is likely to vary considerably across producers. The production approach to estimating markups and marginal cost is a natural way to allow for such continuous and heterogeneous effects of competition on firm performance.

In the Bresnahan and Reiss (1991) framework, we inferred from a less than proportional increase in the number of firms with market size that the price-cost margins must have declined with the number of active firms, giving each firm a harder time to recover fixed costs. If price-cost margins were observable, we could investigate this directly by regressing them on variables that influence the relevant market size, for example trade barriers.

In the structure-conduct-performance paradigm in the IO literature, it was customary to take markup information directly from company accounts. Nickell (1996) is a recent example treating the Lerner index as directly observable and Tybout and Westbrook (1995) is a comparable example from the trade literature. Genesove and Mullin (1998) uses such information to evaluate the demand-side approach to recover price-cost margins.

As an alternative, De Loecker and Warzynski (2012) propose a methodology to recover the firm-specific price-cost margin $(\mu \equiv P / M C)$, as the ratio of the physical output elasticity a firm faces when changing a variable input, say material inputs and intermediates $(M)$, and the corresponding 
revenue share of that input, i.e.

$$
\mu \equiv \frac{P}{M C}=\frac{\theta^{M}}{s_{M}},
$$

with $\theta^{M} \equiv \frac{\partial \ln Q}{\partial \ln M}$ and $s_{M}=\left.\frac{W M}{P Q}\right|^{8}$ If output prices are directly observed, this approach generates estimates of marginal costs as well.

The intuition is as follows. Holding other inputs constant, a competitive firm will expand its use of input $M$ until the revenue share of $M$ equals the output elasticity, which is naturally declining in $M$. If a firm does not increase $M$ all the way until equality holds, but prefers to produce a lower quantity and raise the output price instead, it indicates the firm is able to exercise market power and charge a price above marginal cost.

Importantly, deviations from perfect competition complicate the identification and estimation of the production technology in the absence of firm-specific output price information. Using deflated revenue rather than then actual output level as dependent variable in the production function inflates the output elasticities. Klette and Griliches (1996) and De Loecker (2011) show how a demand assumption can be used to recover the underlying production function parameters.

Recent work has used data on prices to estimate physical production functions, see Foster, Haltiwanger, and Syverson (2008). De Loecker et al. (2012) further show that an analogue problem arises on the input side. If firms produce differentiated products they are likely to rely on differentiated inputs as well, and therefore input prices will also vary across producers. They propose a methodology to estimate (multi-product) physical production function where input price variation, conditional on geography and exogenous factors, stems from quality variation across products and producers.

The production approach has its own limitations, of course. The main one is the need to flexibly identify the shape of technology. In the CobbDouglas case, all variation in input shares are interpreted as market power, which would be unreasonable. On the positive side, there has been a tremendous amount of work on the estimation of production functions in a wide range of industries and countries. The output elasticity estimates can be subjected to a wide range of robustness checks varying the model specifi-

\footnotetext{
${ }^{8}$ Note that the sum of revenue shares over all inputs will not sum to one if a firm has market power as total revenue $(P Q)$ will exceed total cost.
} 
cation and estimation procedure. Results from the demand-side approach can in principle be subjected to a similar robustness analysis by varying the mode of competition and the functional form of demand, but there is a tendency in the empirical IO literature to stick with the static Nash in prices model and a linear random utility specification.

In recent work De Loecker and Scott (2015) compare markups obtained from the production and demand approach for the US beer industry. Both approaches yield very similar average markups for different brewers. It suggests one can rely on either the demand or production approach, depending on the data availability and the particular research question.

\subsection{Effect of trade on productivity and market power}

Some studies have investigated the impact of trade liberalization-tariff reductions-on domestic market power. Examples of such analysis are De Loecker et al. (2012) for India, Brandt, Van Biesebroeck, Wang, and Zhang (2014) for China, and De Loecker, Fuss, and Van Biesebroeck (2014) for Belgium. In the latter application, not only tariff changes are exploited as exogenous changes in the extent of foreign competition, but also the proximity to the border interacted with relative wage evolutions between Belgium and its neighbors.

Some studies have looked at the price-cost margins of exporters in both the cross section and in the time series, see for example De Loecker and Warzynski (2012) and Garcia Marin and Voigtländer (2013), From a reduced form regression to describe the equilibrium relationship between markups and a firm's export status they conclude that exporters tend to have higher markups and that markups increase following export market entry. The challenge in this literature is to identify the mechanism and the causality behind this correlation. Export entry is clearly not an exogenous event and additional structure is needed for causal inference, such as an export selection equation in Van Biesebroeck (2005) or a matching algorithm in De Loecker (2007)

To get at the causal effect of international competition on firm performance, De Loecker et al. (2012) study the impact of the extensive and unexpected trade reforms in India on markups, marginal cost and prices. They do not use productivity itself as a dependent variable, but note that marginal cost will combine the effect of production efficiency and input 
prices. They run separate regressions for all three dependent variables and follow Amiti and Konings (2007) allowing for separate effects from tariffs on final products (output tariffs, $\tau^{O}$ ) and tariffs on inputs (input tariffs, $\tau^{I}$ ). Brandt et al. (2014) perform a similar analysis investigating the impact of Chinese tariff reductions around the time of WTO entry. Due to data limitations, they use markups and productivity at the firm rather than the product level and prices at the sector level.

The price regression does not contain any estimated variables and both studies find that output prices decline with tariffs. At the same time, De Loecker et al. (2012) find a very strong relationship between input tariffs and marginal costs. Naturally, as input prices fall, this has a direct downward impact on firms' marginal cost of production.

The same input tariff decline also impacts markups. All things equal, it is found to raise markups, indicating that cost savings are not fully passed on to consumers in the form of lower final product prices. In the case of China, this effect is only present for younger firms, not for (mostly stateowned) incumbents. The approach taken in these studies underscores the benefits of not committing to a particular demand system and a mode of competition. One can relate markups to the exogenous change in trade protection in a flexible way, and verify whether this affected the competitive pressure faced by domestic producers. 9

\subsection{Extensions based on the pass-through literature}

\subsubsection{Generalizing the markup formula}

The identification of the firm's price-cost margin in equation (3) is related to the way the pass-through literature exploits imperfect price adjustments to infer market power and the (residual) demand elasticity. In some situations researchers have access to marginal cost information or to a large component of it. For example, the wholesale price of a gasoline is a good proxy for a gasoline station's marginal cost. Observing that a firm does not adjust the retail price in line with the wholesale price is an indication of potential market power.

\footnotetext{
${ }^{9}$ In fact with long enough panels we can in theory evaluate this for an individual producer, or at least for a narrow subset of producers. For example, Brandt et al. (2014) find a differential impact of the same foreign competition shock on incumbents and more recently entered firms.
} 
We now make the relationship between these two approaches more explicit. In particular, we illustrate that the market power formula used in the production approach can be derived from the standard practice in the passthrough literature. In the process we derive a formula to estimate markups that generalizes De Loecker and Warzynski (2012).

Under constant returns to scale, Verboven (2012) characterizes the passthrough rate as

$$
\rho=\frac{d P}{d M C}=\frac{\epsilon_{W}}{s_{M}}
$$

It is the ratio of the input price elasticity $\epsilon_{W}=\frac{\partial \ln P}{\partial \ln W}$ to the share of total expenditure on input $M$ in total revenue $\frac{W M}{P Q}$. Under variable return to scale, the expression generalizes to

$$
\rho=\frac{\epsilon_{W}}{s_{M}} \frac{1}{\epsilon_{M}}
$$

with $\epsilon_{M}$ the input demand with respect to output, i.e. the percentage increase in the input demand for each percentage increase in output $\frac{\partial \ln M^{*}}{\partial \ln Q}$.

We can rewrite expression (5) as

$$
\frac{\rho}{\epsilon_{W}}=\frac{\frac{d P}{d M C}}{\frac{\partial \ln P}{\partial \ln W}}=\frac{\frac{\partial \ln Q}{\partial \ln M}}{s_{M}},
$$

which reveals the same right-hand side as in equation (3) 10 Finally, using the pass-through coefficient $\rho$ we can write the markup as follows

$$
\mu=\frac{\frac{\partial \ln Q}{\partial \ln M} \frac{\partial \ln M C}{\partial \ln W}}{s_{M}} .
$$

The additional term in the numerator reflects that the elasticity of the marginal costs with respect to the input price can differ from unity. It generalizes equation (3) to situations where the input price varies with input use, for example due the market power a firm has on its input markets or due to nonlinear input prices such as bulk discounting 12

\footnotetext{
${ }^{10}$ When equation $(3)$ is used in practice, the input share is adjusted for idiosyncratic productivity shocks.

${ }^{11}$ We use that $\rho=\frac{d P}{d M C}=\frac{\partial P}{\partial W} / \frac{\partial M C}{\partial W}=\frac{\partial \ln P}{\partial \ln W} * \frac{P}{M C} / \frac{\partial \ln M C}{\partial \ln W}$

${ }^{12}$ See also Appendix D in De Loecker et al. (2012)
} 


\subsubsection{Interpreting two-step productivity regressions}

The pass-through literature has developed independently from the production-side approach to measuring market power. While the two literatures tend to ask different questions and rely on different data sources, they are both influenced by the same underlying mechanism how variation in the cost of production (including variation in efficiency) shows up in variation in output prices. As production functions are usually estimated using deflated sales and deflated input expenditures, a regression that uses total factor productivity (TFP) as dependent variable will only in special cases recover the impact on firm-level efficiency.

To illustrate this, we start from the production function in (7), where $q$ denotes output and $x$ denotes the vector of inputs, $x=\{l, m, k\}$ labor, intermediate inputs and capital, respectively and productivity $(\omega)$, and $\beta$ is the vector of output elasticities. We rewrite the production function

$$
q_{i t}=\sum_{x} \beta_{x} x_{i t}+\omega_{i t}
$$

to reflect the practice of using deflated variables in empirical work. The price variable $p_{i t}$ is defined as the difference between the firm-level price and the average price for the industry at time $t$. In revenue terms, the production function becomes:

$$
\underbrace{q_{i t}+p_{i t}}_{\tilde{q}_{i t}}=\sum_{x} \beta_{x} \underbrace{\left(x_{i t}+w_{i t}^{x}\right)}_{\tilde{x}_{i t}}+\underbrace{\omega_{i t}+p_{i t}-\sum_{x} \beta_{x} w_{i t}^{x}}_{T F P_{i t}}
$$

where $w^{x}$ denotes the similarly deflated input price of input $x$. Lower case variables indicate logarithms, except for $T F P$ which represents productivity in logarithms, as usual. For simplicity, we limit ourselves to the constant returns to scale case, i.e. $\sum_{x} \beta_{x}=1$.

As an example, consider a regression that attempts to identify the impact of trade liberalization (measured through lower tariffs $(\tau)$, on productivity. Using $\Delta$ to denote the year-on-year change for firm $i, \Delta x=$ $x_{i t}-x_{i t-1}$, we can specify

$$
\begin{aligned}
\Delta p & =\gamma_{0}+\gamma_{1} \Delta w^{x}+\epsilon^{p} \\
\Delta T F P & =\alpha_{0}+\alpha_{1} \Delta \tau+\epsilon^{\omega} .
\end{aligned}
$$


To focus on the particular mechanism of interest consider a local industry using imported inputs. An example would be a local construction industry that relies on imported steel. Let the industry only be subject to an input tariff reduction, which directly translates into an equal change in the input price of materials, such that $\Delta \tau=\Delta w^{M}$. Our interest is in the interpretation of the coefficient on the input tariff in the productivity regression:

$$
\alpha_{1}=\frac{\partial E(T F P)}{\partial \tau} .
$$

In the trade literature this parameter is supposed to measure the productivity effects of a tariff reduction ${ }^{13}$ However, under the assumptions above the estimate $\hat{\alpha}_{1}$ equals:

$$
\hat{\alpha}_{1}=\frac{\partial E(\Delta \omega)}{\partial \Delta \tau}+\frac{\partial E(\Delta p)}{\partial \Delta w^{M}}-\beta_{M} .
$$

We can write the difference between the estimate and the true efficiency effect in terms of the pass-through parameter $\tilde{\rho}$, introduced above, ${ }^{14}$ as follows:

$$
\hat{\alpha}_{1}-\frac{\partial E(\Delta \omega)}{\partial \Delta \tau}=\tilde{\rho} \times s_{M}-\beta_{M} .
$$

The extent to which we get a biased estimate of the efficiency response varies by the extent of market power a firm has. Under perfect competition, $\tilde{\rho}=1$ and $s_{M}=\beta_{M}$ such that the right-hand side is zero and $\hat{\alpha}_{1}$ correctly identifies the efficiency effect. Under monopolistic competition and CES demand it holds that $\tilde{\rho}=1$ and $\beta_{M}=s_{M} \bar{\mu}$, with $\bar{\mu}$ the constant markup. As a result, the bias equals $s_{M}(1-\bar{\mu})<0$ and $\hat{\alpha}_{1}$ underestimates the true efficiency effect. In an oligopolistic industry with downward sloping demand, $\tilde{\rho} \neq 1$ and $\beta_{M}=s_{M} \mu$, such that there will be a bias but it cannot be signed in general.

Using the same equation (10) in a different situation where inputs are sourced locally, but $\Delta \tau$ represents a reduction in the output tariff, the estimated response in the productivity regression amounts to:

$$
\hat{\alpha}_{1}=\frac{\partial E(\Delta \omega)}{\partial \Delta \tau^{O}}+\frac{\partial E(\Delta p)}{\partial \Delta \tau^{O}} .
$$

\footnotetext{
${ }^{13}$ See De Loecker (2011) for more details on this so-called two-stage approach in the productivity literature and Pavcnik (2002) for a well-known example.

${ }^{14}$ Note that in equation (4) $\rho$ is defined in absolute terms-the change in price with marginal costs-while we here use the log-change or percentage pass-through $\tilde{\rho}$ (recall that in our notation $p=\ln P$ ).
} 
The second term is now a competition effect. As output tariffs fall, all things equal, domestic firms face a lower residual demand. They might adjust to this different situation by taking actions to raise their efficiency level, which will be captured by the first term, but this is likely to take some time. If firms have any market power they will also adjust their prices. Effects from equation (9) will thus spillover on the estimates in equation (10). The extent of price adjustment will depend on the nature of competition and on the substitutability between foreign and domestic products, as analyzed in the demand-side literature.

While these effects are illustrated under a variety of simplifying assumptions, the result is general. The estimated effect of increased globalization on productivity will in general be a combination of an actual efficiency response ${ }^{15}$ imperfect pass-through of cost changes in prices, and an impact of competition on output prices.

The setting we used to discuss the different effects is not the dominant one in the trade literature. Traditionally, the impact of trade liberalization on TFP is mainly viewed as efficiency-enhancing, for example leading to a reduction in $\mathrm{X}$-inefficiency. Implicitly, the first terms in equations (12) and (14) are considered the most important. If all markets were perfectly competitive, this would be warranted, but absent that assumption there is little direct evidence for a strong efficiency impact.

\section{Concluding remarks}

In this chapter we highlighted that standard measures of productivity capture not only physical efficiency, but also market power, and variation in output and input prices. As this conflation of effects is largely driven by data constraints which are not likely to be resolved any time soon, we need to study issues like the impact of trade liberalization in a coherent framework that allows for both efficiency and price (be it output or input) responses to increased competition.

This chapter has presented a somewhat different view on what has been a long and heavily researched topic in applied economics. Rather than re-

\footnotetext{
${ }^{15}$ In principle this includes both changes in X-inefficiency and the result of investments in new technology and better products, but the latter channels further complicate the identification and estimation of productivity - see Aw, Roberts, and Xu (2011) and De Loecker (2013) for endogenous productivity processes.
} 
viewing the many studies that regress revenue-based measures of TFP on trade policy or trade intensity variables, we discussed how common empirical approaches in the Industrial Organization literature (on demand estimation and entry) and theoretical models in International Trade can inform empirical researchers on trade-induced firm-level changes that are likely to end up in measured productivity. We also discussed a recently developed framework to estimate markups (and its components marginal cost and productivity) from micro production data; and how in particular it can be used to study the impact of increased competition on firm performance, and thus productivity.

Future research can, and we feel should, further explore the relationship among the various measures of firm performance in one integrated and internally consistent framework. The access to micro data covering a panel of producers across a variety of industries and countries paired with recent advances in the estimation of production functions and market power can help accomplish this.

More specifically, a first important avenue for future work would be to study the role of imported intermediate inputs or the location of economic activity (i.e. firm entry) as alternative ways in which international competition affects the domestic economy. Some work is already proceeding in this area, but the interaction between efficiency and market power tends to be ignored. This is problematic as firms can use higher quality (imported) inputs or favorable locations to differentiate themselves and increase or gain market power.

Endogenous productivity responses to trade liberalization in the context of imperfectly competitive product and input markets is another topic that is currently under-researched. Several studies measure the size of the effect on productivity, but identifying the firm responses that accomplish the measured change are equally important. Here again, the distinction between changes in prices and efficiency as alternative ways to improve price-cost margins is highly relevant.

In the last section we highlighted the potential biases or difficulty in interpreting point estimates when one regresses revenue-based measures of productivity on policy variables, such as tariffs. The first two methods, starting from the demand side or the extensive margin, aim to recover marginal costs directly. Relating these cost estimates to policy variables avoids conflating efficiency effects of international competition with price 
effects. Katayama, Lu, and Tybout (2009) highlight that these cost estimates are quite different from productivity, but it would be useful as well to know how they have responded to exogenous changes in competition, such as following trade liberalizations.

A final research avenue we believe to be promising is to study the distinction between local and global competition. Researchers have often used tariff changes or measures of FDI as exogenous and directly observable indications of a change in the strength of competition that firms face. It leaves open the question whether domestic or international competition has similar effects. Perhaps competition is highly localized and increasing the geographical distance from other firms gradually reduces competitive pressure. However, it is also possible that competition is disrupted by administrative barriers, such as national borders or free trade zones, and competitive effects change discretely at that point. Whether the effect of distance grows continuously or discretely, it is even unclear whether it is the distance from consumers to the location of production or to the location of firm headquarters or sales offices that matters most.

We like to end with the observation that market definition has received less attention that it deserves in the context of international competition. In many cases, the statistical classification that comes with the data, as developed by statistical agencies also determines the market definition used. Such ad hoc classification of industries become even more problematic when the importance of market power is considered explicitly. The production approach does not suffer from such a data constraint, but instead requires one to group firms based on similarities in production technology; very much like the demand approach requires to group the set of products considered part of the relevant market. 


\section{References}

Amiti, M. and J. Konings (2007). Trade liberalization, intermediate inputs and productivity: Evidence from Indonesia. American Economic Review 97(5), 1611-1638.

Arkolakis, C., A. Costinot, D. Donaldson, and A. Rodriguez-Clare (2015). The elusive pro-competitive effects of trade. NBER Working Paper No. 21370, www.nber.org/papers/w21370.

Arkolakis, C., A. Costinot, and A. Rodriguez-Clare (2012). New trade models, same old gains? American Economic Review 102(1), 94-130.

Aw, B. Y., M. J. Roberts, and D. Y. Xu (2011). R\&D investment, exporting, and productivity dynamics. American Economic Review 101(4), 131244.

Berry, S. (1994). Estimating discrete choice models of product differentiation. RAND Journal of Economics 25(2), 242-262.

Berry, S., J. Levinsohn, and A. Pakes (1995). Automobile prices in market equilibrium. Econometrica 63(4), 841-890.

Berry, S., J. Levinsohn, and A. Pakes (1999). Voluntary export restraints on automobiles: Evaluating a strategic trade policy. American Economic Review 89(3), 400-430.

Berry, S. T. and J. Waldfogel (1999). Free entry and social inefficiency in radio broadcasting. RAND Journal of Economics 30(3), 397-420.

Brambilla, I. (2005). A Customs Union with multinational firms: The automobile market in Argentina and Brazil. NBER Working Paper No. 11745, www.nber.org/papers/w11745.

Brandt, L., J. Van Biesebroeck, L. Wang, and Y. Zhang (2014). The impact of entry into WTO on Chinese enterprise productivity. CEPR Discussion Paper No. 9166, www.cepr.org/active/publications/discussion_papers/dp.php? dpno $=9166$.

Bresnahan, T. F. (1987). Competition and collusion in the American automobile oligopoly: The 1955 price war. Journal of Industrial Economics 35(4), 457-482.

Bresnahan, T. F. and P. C. Reiss (1990). Entry and competition in concentrated markets. Review of Economic Studies 57(4), 531-553. 
Bresnahan, T. F. and P. C. Reiss (1991). Entry and competition in concentrated markets. Journal of Political Economy 99(5), 977-1009.

Collard-Wexler, A. and J. De Loecker (2015). Reallocation and technology: Evidence from the us steel industry. American Economic Review 105(1), 131-171.

Corts, K. S. (1999). Conduct parameters and the measurement of market power. Journal of Econometrics 88, 227-250.

De Loecker, J. (2007). Do exports generate higher productivity? Evidence from Slovenia. Journal of International Economics 73(1), 69-98.

De Loecker, J. (2011). Product differentiation, multiproduct firms, and estimating the impact of trade liberalization on productivity. Econometrica 79(5), 1407-1451.

De Loecker, J. (2013). Detecting learning by exporting. American Economic Journal: Microeconomics 5(3), 1-21.

De Loecker, J., C. Fuss, and J. Van Biesebroeck (2014). International competition and firm performance: Evidence from Belgium. National Bank of Belgium Working Paper No. 269, www.nbb.be/doc/ts/publications/wp/wp269en.pdf.

De Loecker, J. and P. K. Goldberg (2014). Firm performance in a global market. Annual Review of Economics 6(1), 201-227.

De Loecker, J., P. K. Goldberg, A. K. Khandelwal, and N. Pavcnik (2012). Prices, markups and trade reform. NBER Working Paper No. 17925, www.nber.org/papers/w17925.

De Loecker, J. and P. T. Scott (2015). Estimating market power. Evidence from the US beer industry. mimeo.

De Loecker, J. and F. Warzynski (2012). Markups and firm-level export status. American Economic Review 102(6), 2437-2471.

Eckel, C. and J. P. Neary (2010). Multi-product firms and flexible manufacturing in the global economy. Review of Economic Studies 77(1), 188-217.

Edmond, C., V. Midrigan, and D. Y. Xu (2015). Competition, markups, and the gains from international trade. American Economic Review (forthcoming), www.nber.org/papers/w18041.pdf. 
Eizenberg, A. (2014). Upstream innovation and product variety in the U.S. home PC market. Review of Economic Studies 81(3), 1003-1045.

Eslava, M., J. Haltiwanger, A. Kugler, and M. Kugler (2004). The effects of structural reforms on productivity and profitability enhancing reallocation: Evidence from Colombia. Journal of Development Economics $75,333-371$.

Fehrstman, C. and N. Gandal (1998). The effect of the Arab boycott on Israel: The automobile market. RAND Journal of Economics 29(1), 193214.

Foster, L., J. Haltiwanger, and C. Syverson (2008). Reallocation, firm turnover, and efficiency: Selection on productivity or profitability? American Economic Review 98(1), 394-425.

Friberg, R. and M. Ganslandt (2006). An empirical assessment of the welfare effects of reciprocal dumping. Journal of International Economics 70(1), 1-24.

Gao, H., J. Van Biesebroeck, and F. Verboven (2014). Strategic trade liberalization. KU Leuven Working Paper, https:/ / feb.kuleuven.be/userpagecv/u0073463/STL.pdf.

Garcia Marin, A. and N. Voigtländer (2013). Exporting and plant-level efficiency gains: It's in the measure. NBER Working Paper No. 19033, www.nber.org/papers/w19033.

Genesove, D. and W. P. Mullin (1998). Testing static oligopoly models: Conduct and cost in the sugar industry, 1890-1914. RAND Journal of Economics 29(2), 355-377.

Goettler, R. L. and B. R. Gordon (2011). Does AMD spur Intel to innovate more? Journal of Political Economy 119(6), 1141-1200.

Goldberg, P. K. (1995). Product differentiation and oligopoly in international markets: The case of the U.S. automobile industry. Econometrica 63(4), 891-951.

Goldberg, P. K. and M. M. Knetter (1997). Goods prices and exchange rates: What have we learned? Journal of Economic Literature 35(3), 1243-1272.

Goldberg, P. K. and F. Verboven (2001). The evolution of price dispersion in the European car market. Review of Economic Studies 68(4), 811-48. 
Hashmi, A. R. and J. Van Biesebroeck (2014). The relationship between market structure and innovation in industry equilibrium: A case study of the global automobile industry. Review of Economics and Statistics (forthcoming), .

Holmes, T. J. and J. A. Schmitz (2001). Competition at work: Railroads vs. monopoly in the U.S. shipping industry. Federal Reserve Bank of Minneapolis Quarterly Review 25(2), 3-29.

Holmes, T. J. and J. A. Schmitz (2010). Competition and productivity: A review of evidence. Annual Review of Economics 2, 619-642.

Irwin, D. A. and N. Pavcnik (2004). Airbus versus Boeing revisited: International competition in the aircraft market. Journal of International Economics 64(2), 223-245.

Katayama, H., S. Lu, and J. R. Tybout (2009). Firm-level productivity studies: Illusions and a solution. International Journal of Industrial Organization 27(3), 403-413.

Khandelwal, A. (2010). The long and short (of) quality ladders. Review of Economic Studies 77(4), 1450-1476.

Kitano, T. and H. Ohashi (2009). Did US safeguards resuscitate HarleyDavidson in the 1980s? Journal of International Economics 79(2), 189197.

Klette, T. J. and Z. Griliches (1996). The inconsistency of common scale estimators when output prices are unobserved and endogenous. Journal of Applied Econometrics 11(4), 343-361.

Konings, J. and H. Vandenbussche (2008). Heterogeneous responses of firms to trade protection. Journal of International Economics 76(2), 371383.

Krugman, P. R. (1979). Increasing returns, monopolistic competition, and international trade. Journal of international Economics 9(4), 469-479.

Lileeva, A. and D. Trefler (2010). Improved access to foreign markets raises plant-level productivity ... for some plants. Quarterly Journal of Economics 125(3), 1051-1099.

Melitz, M. J. (2003). The impact of trade on intra-industry reallocations and aggregate industry productivity. Econometrica 71(6), 1695-1725.

Melitz, M. J. and G. I. P. Ottaviano (2008). Market size, trade, and productivity. Review of Economic Studies 75(1), 295-316. 
Nickell, S. J. (1996). Competition and Corporate Performance. Journal of Political Economy 104(4), 724-746.

Park, M. and H. Rhee (2014). Effects of FTA provisions on the market structure of the Korean automobile industry. Review of Industrial Organization 45(1), 39-58.

Pavcnik, N. (2002). Trade liberalization, exit, and productivity improvement: Evidence from Chilean plants. Review of Economic Studies 69(1), 245-276.

Reynaert, M. and F. Verboven (2014). Improving the performance of random coefficients demand models: The role of optimal instruments. Journal of Econometrics 179(1), 83-98.

Salvo, A. (2010). Inferring market power under the threat of entry: The case of the Brazilian cement industry. RAND Journal of Economics 41(2), 326-350.

Schaumans, C. and F. Verboven (2015). Entry and competition in differentiated products markets. Review of Economics and Statistics 97(1), 195-209.

Sheu, G. (2014). Price, quality, and variety: Measuring the gains from trade in differentiated products. American Economic Journal: Applied Economics 6(4), 66-89.

Syverson, C. (2004). Market structure and productivity: A concrete example. Journal of Political Economy 112(6), 1181-1222.

Thomas, C. (2011). Too many products: Decentralized decision making in multinational firms. American Economic Journal: Microeconomics 3(1), 280-306.

Tovar, J. (2012). Consumers welfare and trade liberalization: Evidence from the car industry in Colombia. World Development 40(4), 808-820.

Tybout, J. R. and M. D. Westbrook (1995). Trade liberalization and the dimensions of efficiency change in Mexican manufacturing industries. Journal of International Economics 39, 53-78.

Van Biesebroeck, J. (2005). Exporting raises productivity in sub-Saharan African manufacturing firms. Journal of International Economics 67(2), 373-391.

Verboven, F. (2012). Competition Analysis - Models and Tools. https://sites.google.com/site/frankverbo/manuscript. 